\title{
Differential contribution of electrically evoked dorsal root reflexes to peripheral vasodilatation and plasma extravasation
}

\author{
Oleg V Lobanov, Yuan B Peng*
}

\begin{abstract}
Background: Dorsal root reflexes (DRRs) are antidromic activities traveling along the primary afferent fibers, which can be generated by peripheral stimulation or central stimulation. DRRs are thought to be involved in the generation of neurogenic inflammation, as indicated by plasma extravasation and vasodilatation. The hypothesis of this study was that electrical stimulation of the central stump of a cut dorsal root would lead to generation of DRRs, resulting in plasma extravasation and vasodilatation.

Methods: Sprague-Dawley rats were prepared to expose spinal cord and L4-L6 dorsal roots under pentobarbital general anesthesia. Electrical stimulation of either intact, proximal or distal, cut dorsal roots was applied while plasma extravasation or blood perfusion of the hindpaw was recorded.

Results: While stimulation of the peripheral stump of a dorsal root elicited plasma extravasation, electrical stimulation of the central stump of a cut dorsal root generated significant DRRs, but failed to induce plasma extravasation. However, stimulation of the central stump induced a significant increase in blood perfusion.

Conclusions: It is suggested that DRRs are involved in vasodilatation but not plasma extravasation in neurogenic inflammation in normal animals.
\end{abstract}

\section{Background}

Somatosensory information is generally considered to originate in the peripheral terminals of primary afferent neurons, and is then transmitted to the spinal cord or brain. However, activity in primary afferent neurons can be generated within the spinal cord, and the impulses can travel antidromically toward the periphery. These phenomena are called dorsal root reflexes (DRR). Dorsal root reflexes were first discovered by Gotch and Horsley [1], and were studied extensively in later works [2-9].

DRRs are thought to contribute to neurogenic inflammation. The main components of neurogenic inflammation include, but are not limited to, arteriolar vasodilatation and plasma extravasation. Neurogenic inflammation is triggered by substances released from sensory nerve terminals, including substance $\mathrm{P}(\mathrm{SP})$ and calcitonin gene-related peptide (CGRP). SP, as

\footnotetext{
* Correspondence: ypeng@uta.edu

* Correspondence: ypeng@uta.edu
Department of Psychology, University of Texas at Arlington, Arlington, TX 76019, USA
} 76019, USA

\section{()

well as other tachykinins such as neurokinin A (NKA) and neurokinin $B(\mathrm{NKB})$, cause plasma extravasation by a specific action on $\mathrm{NK}_{1}, \mathrm{NK}_{2}$, and $\mathrm{NK}_{3}$ receptors [10] to increase vascular permeability [11-13]. SP and NKA play a major role in the periphery, whereas NKB is mainly found in the CNS [14]. CGRP is active in dilating cutaneous arterioles [15] via the $\mathrm{CGRP}_{1}$ receptor $[11,13]$. Both tachykinins and CGRP are found in the peripheral endings of sensory nerves [16-19] and released from both $\mathrm{C}$ and $\mathrm{A} \delta$ fibers [11].

Neurogenic inflammation has been shown to be caused by antidromic electrical stimulation of afferent nerves [20-26], by intradermal injection of capsaicin [27], and in acute [28-31] or chronic [32] arthritis experiments. Enhanced afferent discharges cause the central terminals of primary afferent fibers to release excitatory amino acids, which then activate non-NMDA and NMDA receptors on GABAergic interneurons, leading to the release of GABA on primary afferent central terminals [33-36]. GABA produces excessive primary afferent depolarization (PAD) through $\mathrm{GABA}_{\mathrm{A}}$ receptors 
located on presynaptic terminals of primary afferents $[37,38]$. When PAD exceeds the threshold, DRRs are generated $[39,40]$, which are conducted antidromically in both myelinated and unmyelinated fibers toward the periphery $[41,42]$, and can be blocked by the spinal $\mathrm{GABA}_{\mathrm{A}}$ antagonist, bicuculline [43]. This antidromic activity could result in the release of inflammatory mediators (e.g., SP), as was shown in the knee joint $[23,44]$.

DRRs can be induced by electrical stimulation of peripheral nerves, both ipsilaterally and contralaterally [45], as well as by supraspinal stimulation of the periaqueductal grey [46]. In the present study we tried to mimic the incoming nociceptive input to the spinal cord by electrical stimulation of the central stump of the dorsal root, and test whether the electrically evoked DRRs can contribute to the development of neurogenic inflammation vasodilatation and plasma extravasation. Preliminary results have been reported [47].

\section{Methods}

\section{Animal preparation}

A total of 19 adult male Sprague-Dawley rats weighing 300-400 g were used for this study, 8 for vasodilatation, and 11 for plasma extravasation. All procedures used in this study were approved by the Animal IACUC and followed the guidelines for the treatment of animals of the International Association for the Study of Pain [48].

Animals were initially anesthetized with sodium pentobarbital $(50 \mathrm{mg} / \mathrm{kg}$, i.p.). A catheter was placed into the jugular vein for continuous administration of anesthetic (sodium pentobarbital, $5-8 \mathrm{mg} \cdot \mathrm{kg}^{-1} \cdot \mathrm{h}^{-1}$ in a saline solution) and for Evans Blue injection in plasma extravasation experiments. The level of anesthesia was monitored by the stability of the level of end-tidal $\mathrm{CO}_{2}$ at around $30 \mathrm{mmHg}$ and by the absence of flexion reflex. Tracheotomy was performed for artificial ventilation. The animal's body temperature was maintained at $37^{\circ} \mathrm{C}$ by a feedback controlled electric heating blanket. A 4-cm-long laminectomy was performed over the lumbosacral enlargement to expose the spinal cord and L4-L6 dorsal roots. The rat was held in a stereotaxic frame to prevent movement during recording. The skin over the laminectomy formed a pool and was filled with light mineral oil.

\section{DRR recordings}

A silver wire hook electrode was used to record extracellular single-unit discharges in filaments of the L4 through L6 dorsal roots. A small strand of the dorsal root was teased centrally from the main trunk and was further separated into a fine filament containing one or a few active fibers. This filament was then wrapped around the recording electrode (Figure 1A).
Data recording and analysis was performed by using a CED 1401Plus data acquisition system and SPIKE2 software (Cambridge Electronic Design Ltd, UK).

\section{Electrical stimulation}

Electrical stimulation of the central stump was performed in 16 animals, 8 for plasma extravasation and 8 for laser Doppler measurement. A tripolar electrode was used for electrical stimulation in order to minimize stimulus artifact and to avoid current spread. The cathode was in the middle of the array, and two anodes, one on each side of the cathode, were separated from the cathode by $1 \mathrm{~mm}$ [46]. The L4 or L5 dorsal roots were cut and the central stump was placed on the electrode for electrical stimulation (Figure 1A), while a teased strand from a nearby intact dorsal root was used for recording DRRs. Then stimulation was applied to this central stump of the cut dorsal root for 5 minutes at $20 \mathrm{~V}$, $5 \mathrm{~Hz}, 0.5 \mathrm{~ms}$ pulse duration.

At the end of stimulation of the central stump (L4 or L5) for plasma extravasation, the dorsal root that was used for DRR recording (L5 or L6) was cut and the peripheral stump was stimulated at the same parameters $(20 \mathrm{~V}, 5 \mathrm{~Hz}, 0.5 \mathrm{~ms}$; Figure 1B).

In 3 animals, intact L4 or L5 dorsal root was stimulated at the same parameters $(20 \mathrm{~V}, 5 \mathrm{~Hz}, 0.5 \mathrm{~ms}$; Figure 1C).

\section{Plasma extravasation measurement}

Plasma extravasation measurements were performed in 11 animals, 8 for central and peripheral stump stimulation (Figure 1A) and 3 for intact dorsal root stimulation (Figure $1 C)$. Evans Blue was injected intravenously $(50 \mathrm{mg} / \mathrm{kg}$, using the catheter in the jugular vein) for detection of the sites of plasma extravasation 7 minutes before the start of electrical stimulation. Pictures were taken by an 8 megapixel camera (Nikon Coolpix 8700) on a tripod. Constant light condition, manual set of aperture, and exposure time were maintained during the course of the experiment. Pictures of the plantar side of the rat paw were taken 2 minutes after Evans Blue injections, then every 30 seconds during the course of electrical stimulation and for another 5 minutes or longer after the end of electrical stimulation. Matlab image analysis tool (The MathWorks, Inc., MA) was used to determine the dynamic change of color in the development of plasma extravasation. The whole hindpaw was selected as a region of interest. This method was conceptually similar to a dynamic measurement of plasma extravasation by using $C \mathrm{CD}$ video camera that has been developed recently $[49,50]$.

\section{Cutaneous blood flow measurement}

Changes in cutaneous blood perfusion were measured in 8 animals to detect local vasodilatation (flare) in response to electrical stimulation of the central stump 


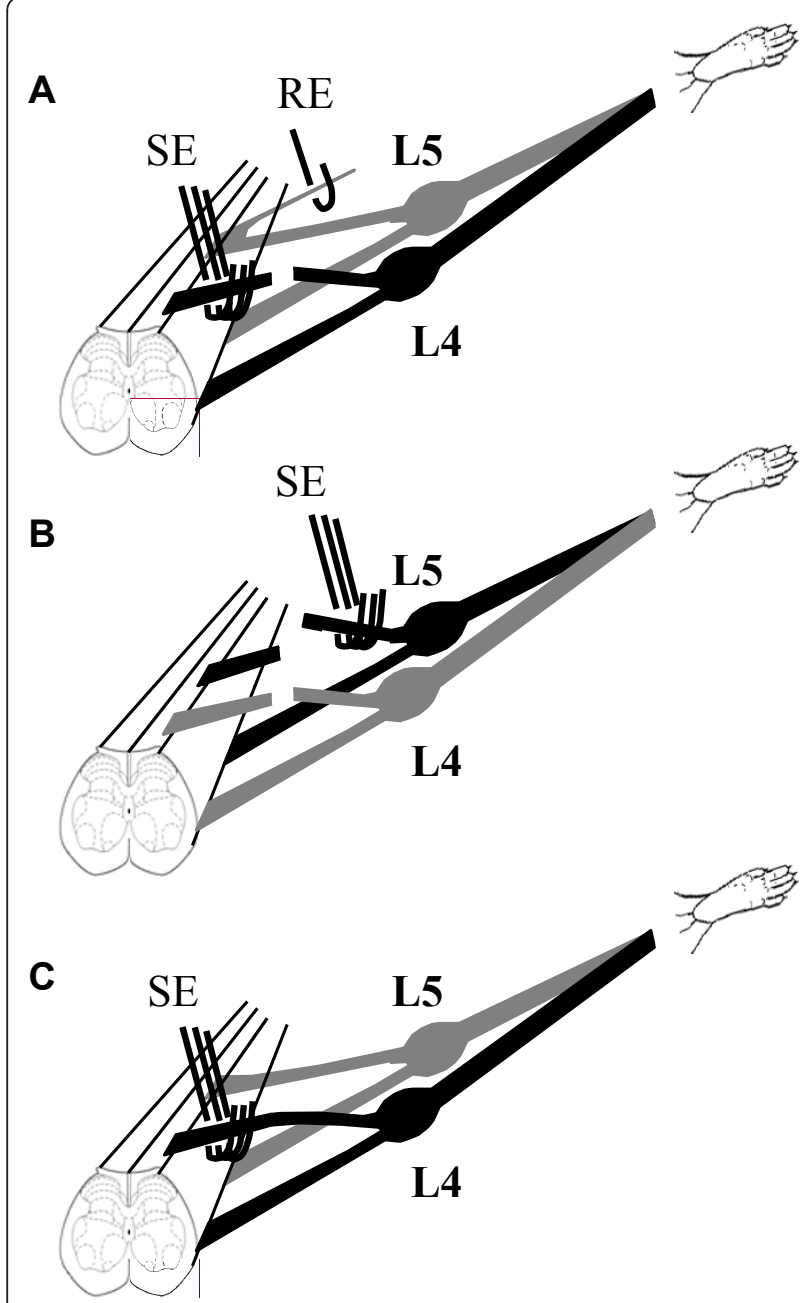

Figure 1 Diagram of the experimental setup. A. The left $L 4$ dorsal root is cut. The central stump is placed over a stimulating electrode (SE) while placing a strand from the left $L 5$ dorsal root on a recording electrode (RE). B. A second cut is made at the left $L 5$ dorsal root. The peripheral stump of the left $L 5$ dorsal root is placed over a stimulating electrode. Seven minutes after Evans Blue injection (i.v.), electrical stimulation ( $20 \mathrm{~V}, 5 \mathrm{~Hz}, 0.5 \mathrm{~ms}$ for $5 \mathrm{~min}$ ) is delivered, while a series of images is taken. $C$. A setup for stimulating an intact dorsal root.

of the L4 or L5 dorsal roots. The measurements were done using Laser Doppler Imager (PeriScan PIM II, Perimed AB, Sweden). After 10 baseline images of the plantar side of the rat hindpaws, continuous scanning were taken during and after stimulation $(20 \mathrm{~V}, 5 \mathrm{~Hz}$, $0.5 \mathrm{~ms}$ pulse duration for 5 minutes) of the central stump of the cut dorsal root. Approximately 20 images were continuously taken after the end of stimulation. It required 2 minutes to acquire one image.

\section{Data analysis}

The stored digital record of unit activity was retrieved and analyzed off-line. The frequency of DRRs was calculated for the periods before $(3 \mathrm{~min})$, during (5 $\mathrm{min}$ ), and after (3 $\mathrm{min})$ the electrical stimulation. Statistical significance was tested using paired t-test.

Matlab software was used in order to measure the intensity of colors on the rat paw. The same region of interest was selected in the set of pictures from each experiment and the change in color intensity in a gray scale was analyzed. The color intensity from Matlab is given as arbitrary unit (AU) for raw data. Normalization was calculated by the following formula: [(color intensity at any time point - color intensity before stimulation) / color intensity before stimulation] $\times 100 \%$. A negative value represents a darker color, suggesting plasma extravasation. One-way ANOVA followed by Posthoc Fisher LSD Test was used to detect significant differences across time as compared to the baseline.

For blood perfusion, the region of interest was selected which covered the whole paw. An average of perfusion (arbitrary unit, AU) in the selected area of each image frame was used for further calculating percentage change. The first 10 images at baseline were averaged as control for subsequent change during and after stimulation: [(blood perfusion at any time point average of first 10 blood perfusion images before stimulation) / average of first 10 blood perfusion images before stimulation] $\times 100 \%$. Repeated measures ANOVA followed by Posthoc Fisher LSD test was used to detect significant differences along the time as compared to the baseline.

All values were presented as means \pm SEM. A change was judged significant if $\mathrm{p}<0.05$.

\section{Results}

Dorsal root reflexes can be elicited at the central dorsal root filaments by electrical stimulation of a neighboring central stump of the cut dorsal root

After the left L4 dorsal root was cut, the central stump was placed on the stimulating electrode. To ensure that DRRs can be elicited, a small fascicle of neighboring dorsal root (usually L5) was teased centrally and was placed in a recording electrode (Figure 1A). Multiunit spontaneous antidromic discharges were recorded from all 8 animals that were tested for plasma extravasation. The discharges were irregular and usually at a very low rate but increased during electrical stimulation of L4 (Figure 2A-C). Average mean spontaneous activity was $0.09 \pm 0.03 \mathrm{~Hz}$ (range: $0-0.22 \mathrm{~Hz} ; \mathrm{n}=8$ ). In most recorded units, additional DRR activity could be evoked by applying a graded mechanical stimulus (brush, pressure, and pinch) to the skin of the foot (data not shown). One cell was found whose receptive field was covering the whole body, as previously reported by others [43,51]. During electrical stimulation $(20 \mathrm{~V}, 5 \mathrm{~Hz}$, $5 \mathrm{~ms}$ ), a significant increase in DRRs was observed 

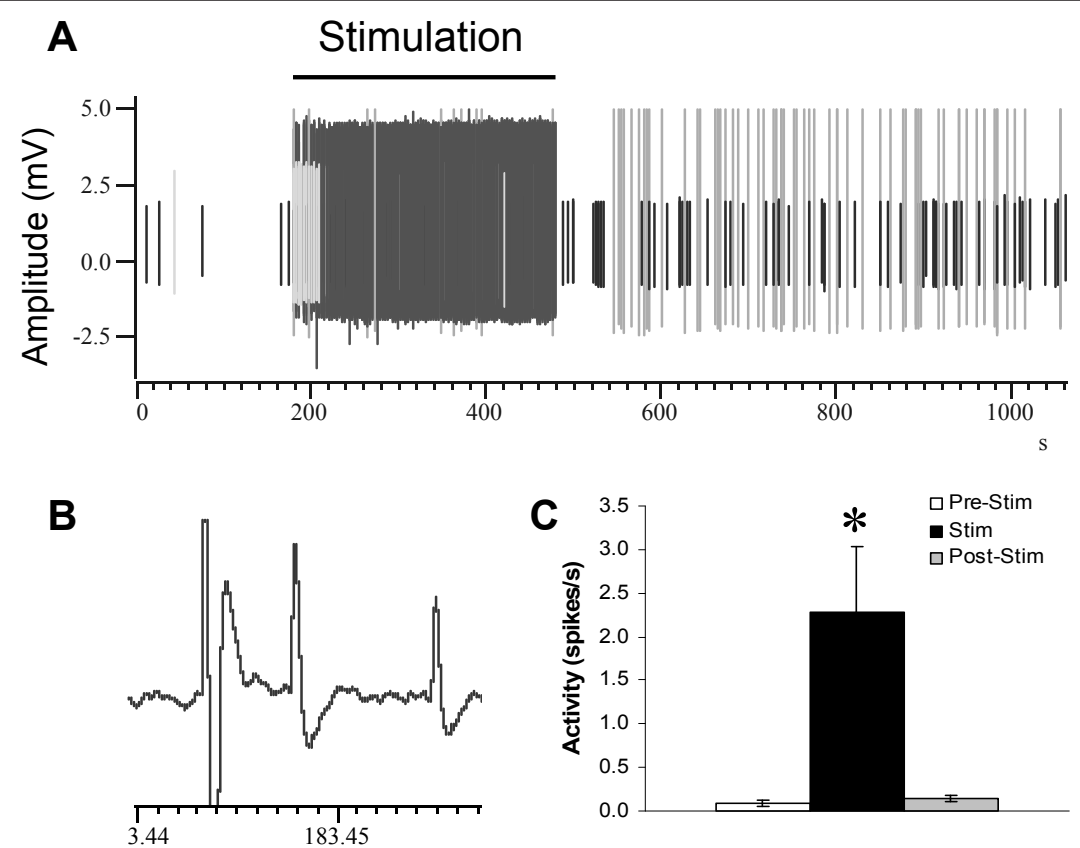

Figure 2 Dorsal root reflexes from a left $\mathbf{L} 5$ filament. A representative strand shows that DRRs can be recorded from the central stump of the dorsal root (L5) while the $L 4$ central stump is stimulated (A). Each vertical line indicates a DRR. In this strand, about 4 fibers show DRR activity, based on their amplitudes and shapes. The horizontal line indicates the duration of electrical stimulation (20 V, $5 \mathrm{~Hz}, 0.5 \mathrm{~ms}$ for $5 \mathrm{~min}$ ). During stimulation, an obvious increase of DRRs is demonstrated, which is summarized in (C). An expanded trace is shown in $B . *: p<0.05$.

(2.28 $\pm 0.76 \mathrm{~Hz}$; range: $0.13-5.27 \mathrm{~Hz} ; \mathrm{n}=8, \mathrm{P}<0.05)$. The activity of antidromic discharges returned to normal $2 \mathrm{~min}(127 \pm 70 \mathrm{~s}$, range from 0 to $585 \mathrm{~s})$ after the termination of electrical stimulation $(0.14 \pm 0.04 \mathrm{~Hz}$; range: $0-0.36 \mathrm{~Hz} ; \mathrm{n}=8$ ). Four out of eight fibers returned to baseline as soon as the stimulation was terminated; one fiber lasted as long as $10 \mathrm{~min}$.

Effects of electrical stimulation of the central stump of the cut dorsal root on plasma extravasation on the plantar surface of the ipsilateral and contralateral hindpaws

When the central stump of the left L4 dorsal root was stimulated, there was no obvious plasma extravasation observed in the ipsilateral (left) paw (Figure $3,1^{\text {st }}$ row) and contralateral (right) paw (Figure $3,2^{\text {nd }}$ row). The color intensities before stimulation were $109.57 \pm 10.02$ in the left paw (Figure 3G) and 103.10 \pm 4.25 AU (arbitrary unit) (Figure $3 G$ ) in the right paw among 8 animals. During and after central left L4 stimulation, the color intensity for the left paw ranged from $113.72 \pm 9.81$ to $116.96 \pm 8.96 \mathrm{AU}$ (Figure 3G); the color intensity for the right paw ranged from $102.57 \pm 4.53$ to $106.43 \pm 3.46 \mathrm{AU}$ (Figure 3G). Data were analyzed by ANOVA to test differences between sides (ipsilateral and contralateral), and among effects of time ( $\mathrm{C}$ to $10 \mathrm{~min}$ ) following central stump stimulation. The results indicated no effect of stimulation side, $\mathrm{F}(1,7)=1.86, \mathrm{p}=0.22$; no effect of time,
$\mathrm{F}(20,140)=1.33, \mathrm{p}=0.17$; and no effect of interaction $($ Side $\times$ Time $), F(20,140)=1.25, \mathrm{p}=0.23$.

By using the color intensity before stimulation to normalize the other data, the percentage change of color intensity of the left paw ranged from $4.31 \pm 2.96$ to $8.00 \pm$ $2.77 \%$ (Figure $3 \mathrm{H}$ ); the percentage change of color intensity of the right paw ranged from $-0.42 \pm 2.31$ to $3.68 \pm$ $2.42 \%$ (Figure $3 \mathrm{H}$ ). Data were analyzed by ANOVA to test differences between sides of central stump stimulation (side: ipsilateral and contralateral), and among effects of time (time: $\mathrm{C}$ to $10 \mathrm{~min}$ ). The results indicated no effect of stimulation side, $\mathrm{F}(1,7)=5.48, \mathrm{p}=0.052$; no effect of time, $\mathrm{F}(20,140)=1.37, \mathrm{p}=0.15$; and no effect of interaction $($ Side $\times$ Time), F $(20,140)=1.23, \mathrm{p}=0.24$.

\section{Effects of electrical stimulation of the peripheral stump of} the cut dorsal root on plasma extravasation on the plantar surface of the ipsilateral hindpaw

When the peripheral stump of the left L5 dorsal root was stimulated, there was obvious plasma extravasation observed in the left paw as demonstrated by blue patches (Figure 3A-F, $3^{\text {rd }}$ row). The color intensity of the left paw before stimulation were $109.57 \pm 10.02$ for central stimulation group ( $\mathrm{n}=8$, Figure $3 \mathrm{G}$ ) and 125.94 \pm 7.10 AU (arbitrary unit) (Figure $3 G$ ) for peripheral stump stimulation group $(n=7)$, respectively. During and after stimulation of peripheral stump of left L5 stimulation, the color intensity 


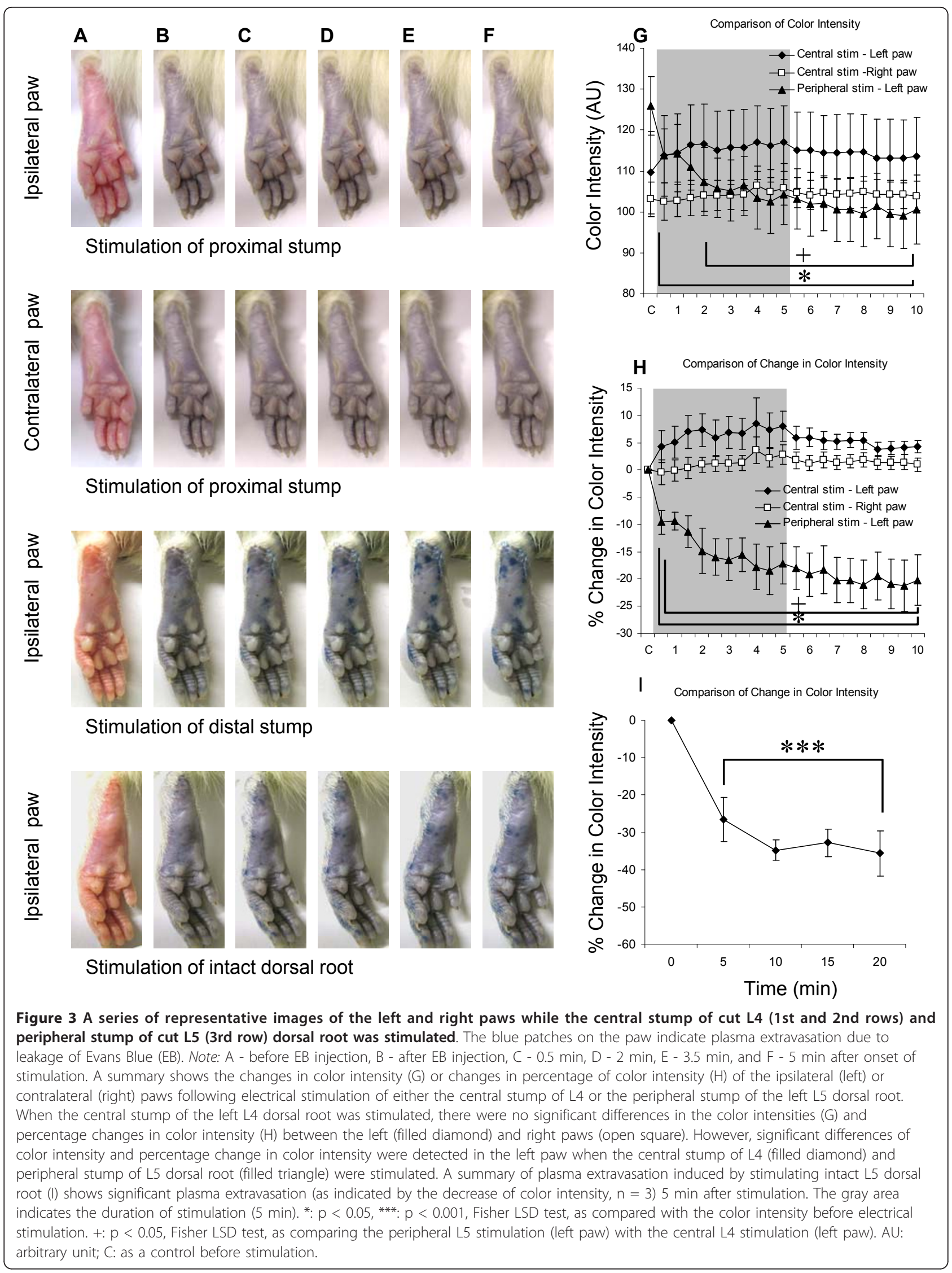


for the left paw dropped as low as $99.05 \pm 8.06$ AU. Data were analyzed by ANOVA to test differences between stimulation site (central vs. peripheral), and among effects of time (time: $\mathrm{C}$ to $10 \mathrm{~min}$ ). The results indicated no effect of stimulation site, $\mathrm{F}(1,6)=0.52, \mathrm{p}=0.5$; a significant effect of time, $\mathrm{F}(20,120)=5.29, \mathrm{p}<0.001$; and a significant effect of interaction (Site $\times$ Time), F $(20,120)=7.96, \mathrm{p}<$ 0.001 . Posthoc Fisher LSD tests indicated significantly lower color intensity in the left paw 2 minutes following stimulation of the peripheral stump of dorsal root $(+: \mathrm{p}<$ 0.05 ) as compared to central stump stimulation (Figure $3 G)$, as well as to before stimulation (*: $\mathrm{p}<0.05)$.

By using the color intensity before stimulation to normalize the other data, the percentage change of color intensity of the left paw dropped to $-21.28 \pm 4.73 \%$ following stimulation of the peripheral stump of dorsal root (Figure $3 \mathrm{H}$ ). Data was analyzed by ANOVA to test differences between sites of stimulation (central vs. peripheral), and among effects of time (time: $\mathrm{C}$ to $10 \mathrm{~min}$ ). The results indicated significant effect of stimulation site, $F(1,6)=19.44, p=0.005$; a significant effect of time, $\mathrm{F}(20,120)=4.20, \mathrm{p}<0.001$; and a significant effect of interaction (Site $\times$ Time), $F(20,120)=6.16$, $\mathrm{p}<0.001$. Posthoc Fisher LSD tests indicated significantly lower intensity in the left paw following stimulation of the peripheral stump of dorsal root $(+: \mathrm{p}<0.05)$ as comparing to central stump stimulation (Figure $3 \mathrm{H}$ ), as well as to before stimulation (*: $\mathrm{p}<0.05)$.

\section{Effects of electrical stimulation of the intact dorsal root on plasma extravasation on the plantar surface of the ipsilateral hindpaw}

When the intact left L4 or L5 dorsal root was stimulated, there was plasma extravasation observed in the left paw ( $n=3$, Figure $3 \mathrm{~A}-\mathrm{F}, 4^{\text {th }}$ row). The color intensity change of the left paw was normalized by using the color intensity before stimulation (Figure 3I). The change of color intensity of the left paw were $-26.63 \pm$ 5.91 at $5 \mathrm{~min},-34.77 \pm 2.81$ at $10 \mathrm{~min},-32.75 \pm 3.69$ at $15 \mathrm{~min}$, and $-35.69 \pm 6.16$ at $20 \mathrm{~min}$ following stimulation, where the negative value indicates an increase in extravasation. Significant changes were found at 5, 10, 15 , and $20 \mathrm{~min}$ after stimulation. One-way ANOVA showed a significant change after stimulation of the intact dorsal root, $\mathrm{F}(4,8)=31.6, \mathrm{p}<0.001$. Posthoc Fisher LSD tests indicated significantly lower intensity in the left paw following stimulation of the intact dorsal root as comparing to before stimulation ( $\left.{ }^{* * * *}: \mathrm{p}<0.001\right)$.

\section{Effects of electrical stimulation of the central stump of the cut dorsal root on vasodilatation on the plantar surface of bilateral hindpaws}

When the central stump of left L4 or L5 dorsal root was stimulated, there was obvious vasodilatation in the left paw (Figure 4A-H). The blood perfusion change of the left paw was normalized from raw data (Figure 4I) using the average of 10 baseline images and summarized (ipsilateral $n=8$, contralateral $n=5$, Figure 4J). Data were analyzed by ANOVA to test differences between hindpaws (ipsilateral vs. contralateral), and among effects of images (image number: 1-34). The results indicated no effect of side of hindpaws, $\mathrm{F}(1,3)=1.66, \mathrm{p}=0.29$; a significant effect of images numbers, $\mathrm{F}(33,99)=2.11, \mathrm{p}=0.002$; and a significant effect of interaction (Side $\times$ Image), F $(33,99)=2.11$, $\mathrm{p}=0.002$. Posthoc Fisher LSD tests indicated significantly higher blood perfusion in the left hindpaw during stimulation of the central stump of dorsal root as compared to the right hindpaw (*: $\mathrm{p}<0.05)$ (Figure $4 \mathrm{I}$ ), as well as to before stimulation $(+: \mathrm{p}<0.05)$.

After normalization, an ANOVA to test differences between hindpaws (ipsilateral vs. contralateral), and among effects of images (image number: 1-34) indicated no effect of side of hindpaws, $F(1,3)=0.16, \mathrm{p}=0.71$; a significant effect of images, $\mathrm{F}(33,99)=2.26, \mathrm{p}=0.001$; and a significant effect of interaction (Side $\times$ Image), $\mathrm{F}$ $(33,99)=2.91, \mathrm{p}<0.001$. Posthoc Fisher LSD tests indicated a significant increase of blood perfusion (Figure 4I) in the left hindpaws during stimulation of the central stump of dorsal root as compared to the right hindpaw $(*: \mathrm{p}<0.05)$, as well as a significant percentage increase (Figure $4 \mathrm{~J}$ ) of blood perfusion in both hindpaws as compared to the baseline $(+: \mathrm{p}<0.05)$.

\section{Discussion}

The goal of the present experiment was to minimize confounders introduced by artificial antidromic stimulation of dorsal root or introduction of substances to the periphery by interrupting the communication of the stimulated dorsal root with periphery. In the past, electrical stimulation of one dorsal root elicited DRRs in the neighboring roots and spread along (up to 16 spinal segment in both directions from the stimulated site) and across the spinal cord [52]. This process is believed to operate in all-or-none manner once activated [53]. Since a rat's paw is innervated by L4-L6 originating nerves, we assumed that stimulating the central portion of one cut dorsal root would evoke DRRs to the ipsilateral paw through the remaining two dorsal roots. In fact, in the current experiment electrical stimulation of the central stump of the dorsal root elicited a significant increase in DRR activity in the recorded fibers of the neighboring dorsal roots.

Neuropeptides (particularly, substance P and CGRP) found in peripheral terminals of nociceptive fibers contribute to neurogenic inflammation and are released in response to antidromic stimulation $[11,13,40,54]$. Therefore, we expected that electrically evoked DRRs in the nerves innervating a rat's paw would produce both 


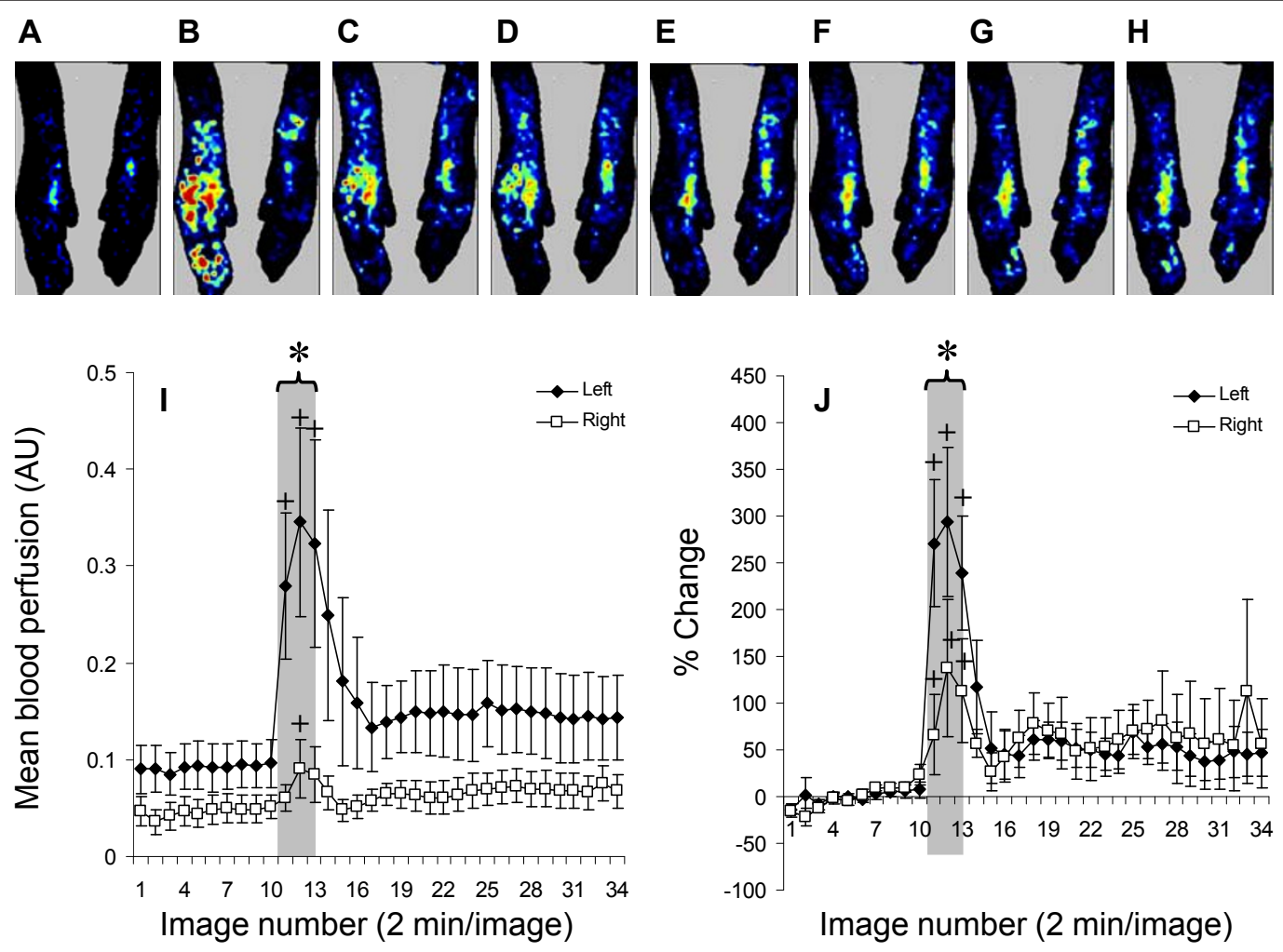

Figure 4 Effect of stimulation of the central stump of the cut dorsal root on blood perfusion in hindpaws bilaterally. The upper panel shows laser Doppler images from one rat as control (A), during stimulation (B-D), and 2 (E), 14 (F), 32 (G), and 52 min (H) after the end of stimulation. Blue color indicates lower perfusion, whereas red color indicates higher perfusion. Time response curves are plotted for the raw data (I) and normalized changes in blood perfusion (J) in both the ipsilateral (Left) and contralateral (Right) hindpaws. The gray area indicates duration of stimulation (from image 11 to 13). Note $+: p<0.05$ as compared to baseline, including all time points under the bracket. ${ }^{*}: p<0.05$ as compared to the right side.

plasma extravasation and vasodilation. However, bilateral vasodilation but not plasma extravasation was observed in response to central stump stimulation.

As previously mentioned, SP acting on tachykinin receptors increases microvascular permeability and edema formation $[10,13]$. CGRP, on the other hand, acting on its receptors produces arteriolar vasodilation $[13,15]$. Interestingly, C-fibers contain both SP and CGRP, whereas $A \delta$-fibers predominantly have CGRP in their peripheral terminals $[17,55,56]$. In addition, antidromic stimulation of the saphenous nerve at $\mathrm{C}$-fiber intensity produces both vasodilation and plasma extravasation, whereas stimulation at A $\delta$-fiber intensity produces only vasodilation [24,54]. It has been previously shown that 1-2 pulses to lumbosacral dorsal roots are enough to cause a change in cutaneous microcirculation, and 4-16 pulses at $2 \mathrm{~Hz}$ evokes vasodilatation lasting for several minutes [20]. Similar results have been shown with spinal cord stimulation [57]. In our study, electrical stimulation of the intact dorsal root or the peripheral stump of the dorsal root produced both vasodilatation and plasma extravasation in the skin. However, electrical stimulation of the central stump with the same parameters did not elicit plasma extravasation on either side, but did produce vasodilatation bilaterally. This finding suggests that the stimulation parameters selected were sufficient to excite both myelinated and unmyelinated fibers in both the distal and central stumps of the dorsal root. However, stimulation of the central stump of the dorsal root triggers more DRRs in myelinated than unmyelinated fibers in the neighboring roots, and leads mostly to CGRP release, and in turn vasodilation.

The differential release of co-localized neurotransmitters from the same terminal depending on the firing rate is another possible explanation of the obtained results. The stimulation frequency needed to induce plasma extravasation is higher than that to produce vasodilation [54]. Electrical stimulation should to some extent mimic peripherally evoked orthodromic action potentials. It is true that DRRs evoked by stimulating the central stump are much weaker than direct stimulation of the distal stump, due to the nature of multisynaptic connectivity inside the spinal cord. It may help to explain the differences in plasma extravasation resulting 
from stimulation of the central versus peripheral stump. In addition, co-packaged in the same granule, catecholamines and neuropeptides have been shown to be differentially released from adrenal medulla depending on the firing rate through a regulated activity-dependent dilation of the granule fusion pore and size-exclusion mechanism [58,59].

In both of the proposed mechanisms, there should be a higher probability of DRR generation in $A \delta$-fibers compared to $\mathrm{C}$-fibers in response to central stump orthodromic stimulation. First, there may be a differential effect of GABA on $\mathrm{GABA}_{\mathrm{A}}$ receptors on the central terminals of primary afferents. C-fibers have been shown to have a lower density of $\mathrm{GABA}_{\mathrm{A}}$ receptors compared to both $A \delta$-fibers and $A \beta$-fibers [60]. Second, the threshold for generation of DRRs by PADs may be higher in $\mathrm{C}$-fibers compared to $\mathrm{A} \delta$ - fibers.

In addition, the proportion of CGRP-containing afferents is much higher compared to SP-containing afferents in the skin. CGRP is present in both myelinated and unmyelinated nociceptive fibers, whereas SP is only found in small diameter unmyelinated fibers. CGRP is also found in larger number of unmyelinated fibers compared to SP [61].

Finally, the role of sympathetic nervous system needs to be addressed, since the stimulation of the central stump may increase sympathetic activity. On one hand, sympathetic activity can decrease neuropeptide release from afferent fibers by its action on prejunctional $\alpha_{2}$ adrenoreceptors [13], and counteract dorsal reflexmediated neurogenic inflammation [62]. On the other hand, sympathetic presence is important for the development of DRR-mediated neurogenic inflammation through the actions of neuropeptide Y (NPY) and norepinephrine on NPY $\mathrm{Y}_{2}$ and alpha $\mathrm{a}_{1}$ receptors, respectively $[63,64]$.

In this study, the contribution of the sympathetic nervous system during central stump stimulation was challenged by two experiments: blood perfusion change in stimulation of the central stump of the cut dorsal root (Figure 4) and plasma extravasation in stimulation of intact dorsal root (Figure 3I). Stimulation of the central stump produced a significant bilateral increase in blood perfusion suggesting that DRRs in primary afferents surpass sympathetic vasoconstriction, if present. Stimulation of intact dorsal root on the other hand (action potentials can travel orthodromically and antidromically) produced plasma extravasation in the ipsilateral hindpaw, suggesting that even if sympathetic system is activated by orthodromic input, its subsequent effects are not strong enough to counteract plasma extravasation induced by the antidromic spikes that reached the periphery.

\section{Conclusion}

In summary, incoming stimulation at an intensity that activates all types of nociceptive fibers produces DRRs in the intact neighboring roots as well as bilateral vasodilation of the innervated area but not plasma extravasation. Neurogenic inflammation is a complex process that requires the co-release of multiple substances. It seems that noxious stimulation alone is not capable of eliciting all signs of neurogenic inflammation. Therefore, successful treatment of neurogenic inflammation will not only require that the neural input to the spinal cord be addressed, but also that co-factors in both spinal cord and the periphery that allow neural input to convert to neuropeptide co-release be addressed. In addition, acutely elicited DRRs are not able to elicit the complete picture of neurogenic inflammation; future studies are necessary to establish the contributions and nature of DRRs in chronic pain states such as arthritis or migraine.

\section{Acknowledgements}

We appreciate the help from Mr. Manan R. Goel for image analysis. This study was supported by Startup Fund and partially by CBC Seed Fund from UTA.

\section{Authors' contributions}

This study is based on the original idea of OVL and YBP. OVL performed data collection, data analysis, the statistical analysis and wrote the manuscript. YBP made contributions to conception and design and analysis and interpretation of data. All authors have read and approved the final manuscript.

\section{Competing interests}

The authors declare that they have no competing interests.

Received: 12 August 2010 Accepted: 28 February 2011 Published: 28 February 2011

\section{References}

1. Gotch F, Horsley V: On the mammalian nervous system, its functions and their localizations, determined by an electrical method. Philosophical transactions of the Royal Society of London Series B, Biological sciences 1891, 276-526.

2. Barron DH, Matthews BHC: "Recurrent fibres" of the dorsal roots. Journal of Physiology 1935, 85:104-108.

3. Barron DH, Matthews BHC: Intermittent conduction in the spinal cord. Journal of Physiology 1935, 85:73-103.

4. Barron DH, Matthews BHC: Dorsal root potentials. Journal of Physiology 1938, 94:27-28P.

5. Barron DH, Matthews BHC: Dorsal root reflexes. Journal of Physiology 1938, 94:26-27P

6. Barron $\mathrm{DH}$, Matthews $\mathrm{BHC}$ : The interpretation of potential changes in the spinal cord. Journal of Physiology 1938, 92:276-321.

7. Langford LA, Coggeshall RE: Branching of sensory axons in the dorsal root and evidence for the absence of dorsal root efferent fibers. The Journal of comparative neurology 1979, 184:193-204.

8. Brooks CM, Koizumi K: Origin of the dorsal root reflex. Journal of Neurophysiology 1956, 19:60-74.

9. Brooks CM, Koizumi K, Malcolm JL: Effects of changes in temperature on reactions of spinal cord. Journal of Neurophysiology 1955, 18:205-216.

10. Iwamoto I, Nadel JA: Tachykinin receptor subtype that mediates the increase in vascular permeability in guinea pig skin. Life Science 1989, 44:1089-1095. 
11. Brain SD: Sensory neuropeptides: their role in inflammation and wound healing. Immunopharmacology 1997, 37:133-152.

12. Majno G, Shea SM, Leventhal M: Endothelial contraction induced by histamine-type mediators: an electron microscopic study. The Journal of cell biology 1969, 42:647-672.

13. Holzer P: Neurogenic vasodilatation and plasma leakage in the skin. General Pharmacology 1998, 30:5-11.

14. Harrison S, Geppetti P: Substance p. The international journal of biochemistry \& cell biology 2001, 33:555-576.

15. Brain SD, Cambridge $\mathrm{H}$ : Calcitonin gene-related peptide: vasoactive effects and potential therapeutic role. General Pharmacology 1996, 27:607-611.

16. Levine JD, Clark R, Devor M, Helms C, Moskowitz MA, Basbaum Al: Intraneuronal substance $\mathrm{P}$ contributes to the severity of experimental arthritis. Science 1984, 226:547-549.

17. Lundberg JM, Franco-Cereceda A, Hua X, Hökfelt T, Fischer JA: Co-existence of substance $\mathrm{P}$ and calcitonin gene-related peptide-like immunoreactivities in sensory nerves in relation to cardiovascular and bronchoconstrictor effects of capsaicin. European Journal of Pharmacology 1985, 108:315-319

18. Maggi CA, Meli A: The sensory-efferent function of capsaicin-sensitive sensory neurons. General Pharmacology 1988, 19:1-43.

19. Holzer P: Peptidergic sensory neurons in the control of vascular functions: mechanisms and significance in the cutaneous and splanchnic vascular beds. Reviews of physiology, biochemistry and pharmacology 1992, 121:49-146.

20. Szolcsányi J: Antidromic vasodilatation and neurogenic inflammation. Agents Actions 1988, 23:4-11.

21. Pinter E, Szolcsányi J: Inflammatory and antiinflammatory effects of antidromic stimulation of dorsal roots in the rat. Agents Actions 1988, 25:240-242.

22. Gee MD, Lynn B, Cotsell B: The relationship between cutaneous C fibre type and antidromic vasodilatation in the rabbit and the rat. Journal of Physiology 1997, 503:31-44.

23. Ferrell WR, Russell NJ: Extravasation in the knee induced by antidromic stimulation of articular C fibre afferents of the anaesthetized cat. Journal of Physiology 1986, 379:407-416.

24. Jänig W, Lisney SJ: Small diameter myelinated afferents produce vasodilatation but not plasma extravasation in rat skin. Journal of Physiology 1989, 415:477-486.

25. Kenins $P$ : Identification of the unmyelinated sensory nerves which evoke plasma extravasation in response to antidromic stimulation. Neuroscience Letters 1981, 25:137-141.

26. Takahashi Y, Nakajima Y: Dermatomes in the rat limbs as determined by antidromic stimulation of sensory C-fibers in spinal nerves. Pain 1996, 67:197-202.

27. Lin Q, Wu J, Willis WD: Dorsal root reflexes and cutaneous neurogenic inflammation after intradermal injection of capsaicin in rats. Journal of Neurophysiology 1999, 82:2602-2611.

28. Rees H, Sluka KA, Westlund KN, Willis WD: Do dorsal root reflexes augment peripheral inflammation? Neuroreport 1994, 5:821-824.

29. Rees H, Sluka KA, Westlund KN, Willis WD: The role of glutamate and GABA receptors in the generation of dorsal root reflexes by acute arthritis in the anaesthetized rat. Journal of Physiology 1995, 484(Pt 2):437-445.

30. Sluka KA, Westlund KN: Centrally administered non-NMDA but not NMDA receptor antagonists block peripheral knee joint inflammation. Pain 1993, 55:217-225.

31. Sluka KA, Lawand NB, Westlund KN: Joint inflammation is reduced by dorsal rhizotomy and not by sympathectomy or spinal cord transection. Annals of the rheumatic diseases 1994, 53:309-314.

32. Rees $H$, Sluka KA, Lu Y, Westlund KN, Willis WD: Dorsal root reflexes in articular afferents occur bilaterally in a chronic model of arthritis in rats. Journal of Neurophysiology 1996, 76:4190-4193.

33. Hayes ES, Carlton SM: Primary afferent interactions: analysis of calcitonin gene-related peptide-immunoreactive terminals in contact with unlabeled and GABA-immunoreactive profiles in the monkey dorsal horn. Neuroscience 1992, 47:873-896.

34. Sluka KA, Willis WD, Westlund KN: The Role of Dorsal Root Reflexes in Neurogenic Inflammation. Pain Forum 1995, 4(3):141-149.

35. Zou X, Lin Q, Willis WD: NMDA or non-NMDA receptor antagonists attenuate increased Fos expression in spinal dorsal horn GABAergic neurons after intradermal injection of capsaicin in rats. Neuroscience 2001, 106:171-182.

36. Zou X, Lin Q, Willis WD: The effects of sympathectomy on capsaicinevoked fos expression of spinal dorsal horn GABAergic neurons. Brain Research 2002, 958:322-329.

37. Curtis DR, Lodge $D$ : The depolarization of feline ventral horn group la spinal afferent terminations by GABA. Experimental Brain Research 1982, 46:215-233.

38. Levy RA: GABA: a direct depolarizing action at the mammalian primary afferent terminal. Brain Research 1974, 76:155-160.

39. Schmidt RF: Presynaptic inhibition in the vertebrate central nervous system. Ergeb Physiol 1971, 63:20-101.

40. Willis WD: Dorsal root potentials and dorsal root reflexes: a doubleedged sword. Experimental Brain Research 1999, 124:395-421.

41. Sluka KA, Rees $H$, Westlund KN, Willis WD: Fiber types contributing to dorsal root reflexes induced by joint inflammation in cats and monkeys. Journal of Neurophysiology 1995, 74:981-989.

42. Lin Q, Zou X, Willis WD: Adelta and C Primary Afferents Convey Dorsal Root Reflexes After Intradermal Injection of Capsaicin in Rats. Journal of Neurophysiology 2000, 84:2695-2698.

43. Peng YB, Wu J, Willis WD, Kenshalo DR: GABA(A) and 5-HT(3) receptors are involved in dorsal root reflexes: possible role in periaqueductal gray descending inhibition. Journal of Neurophysiology 2001, 86:49-58.

44. Yaksh TL: Substance $P$ release from knee joint afferent terminals: Modulation by opioids. Brain Research 1988, 458:319-324.

45. Toennies JF: Reflex discharge from the spinal cord over the dorsal roots. Journal of Neurophysiology 1938, 1:378-390.

46. Peng YB, Kenshalo DR, Gracely RH: Periaqueductal gray-evoked dorsal root reflex is frequency dependent. Brain Research 2003, 976:217-226.

47. Lobanov OV, Peng YB: Differential contribution of electrically-evoked dorsal root reflex to peripheral vasodilatation and plasma extravasation. Society for Neuroscience 2006, 51:11.

48. Zimmermann $\mathrm{M}$ : Ethical guidelines for investigations of experimental pain in conscious animals. Pain 1983, 16:109-110.

49. Carmichael NM, Dostrovsky JO, Charlton MP: Enhanced vascular permeability in rat skin induced by sensory nerve stimulation: Evaluation of the time course and appropriate stimulation parameters. Neuroscience 2008, 153:832-841.

50. Gonzalez HL, Carmichael N, Dostrovsky JO, Charlton MP: Evaluation of the time course of plasma extravasation in the skin by digital image analysis. Journal of Pain 2005, 6:681-688.

51. Weng HR, Dougherty PM: Response properties of dorsal root reflexes in cutaneous C fibers before and after intradermal capsaicin injection in rats. Neuroscience 2005, 132:823-831.

52. Bagust J, Kerkut GA, Rakkah NI: The dorsal root reflex in isolated mammalian spinal cord. Comp Biochem Physiol A 1989, 93:151-160.

53. Bagust J, Chen Y, Kerkut GA: Spread of the dorsal root reflex in an isolated preparation of hamster spinal cord. Experimental Physiology 1993, 78:799-809.

54. Holzer P, Maggi CA: Dissociation of dorsal root ganglion neurons into afferent and efferent-like neurons. Neuroscience 1998, 86:389-398.

55. Hökfelt T, Kellerth JO, Nilsson G, Pernow B: Substance p: localization in the central nervous system and in some primary sensory neurons. Science 1975, 190:889-890

56. Ishida-Yamamoto A, Senba E, Tohyama M: Distribution and fine structure of calcitonin gene-related peptide-like immunoreactive nerve fibers in the rat skin. Brain Research 1989, 491:93-101.

57. Wu M, Komori N, Qin C, Farber JP, Linderoth B, Foreman RD: Roles of peripheral terminals of transient receptor potential vanilloid-1 containing sensory fibers in spinal cord stimulation-induced peripheral vasodilation. Brain Research 2007, 1156:80-92.

58. Fulop T, Radabaugh S, Smith C: Activity-dependent differential transmitter release in mouse adrenal chromaffin cells. Journal of Neuroscience 2005, 25:7324-7332.

59. Chan SA, Doreian B, Smith C: Dynamin and myosin regulate differential exocytosis from mouse adrenal chromaffin cells. Cell Mol Neurobiol 2010, 30:1351-1357.

60. Desarmenien M, Santangelo F, Loeffler JP, Feltz P: Comparative study of GABA-mediated depolarizations of lumbar A delta and C primary afferent neurones of the rat. Experimental Brain Research 1984, 54:521-528. 
61. Gibbins IL, Wattchow D, Coventry B: Two immunohistochemically identified populations of calcitonin gene-related peptide (CGRP)immunoreactive axons in human skin. Brain Research 1987, 414:143-148.

62. Häbler HJ, Wasner $G$, Jänig W: Interaction of sympathetic vasoconstriction and antidromic vasodilatation in the control of skin blood flow. Experimental Brain Research 1997, 113:402-410.

63. Wang J, Ren Y, Zou X, Fang L, Willis WD, Lin Q: Sympathetic influence on capsaicin-evoked enhancement of dorsal root reflexes in rats. Journal of Neurophysiology 2004, 92:2017-2026

64. Lin Q, Zou X, Ren Y, Wang J, Fang L, Willis WD: Involvement of peripheral neuropeptide $Y$ receptors in sympathetic modulation of acute cutaneous flare induced by intradermal capsaicin. Neuroscience 2004, 123:337-347.

doi:10.1186/1742-2094-8-20

Cite this article as: Lobanov and Peng: Differential contribution of electrically evoked dorsal root reflexes to peripheral vasodilatation and plasma extravasation. Journal of Neuroinflammation 2011 8:20.

\section{Submit your next manuscript to BioMed Central} and take full advantage of:

- Convenient online submission

- Thorough peer review

- No space constraints or color figure charges

- Immediate publication on acceptance

- Inclusion in PubMed, CAS, Scopus and Google Scholar

- Research which is freely available for redistribution

Submit your manuscript at www.biomedcentral.com/submit 